\title{
The Effect of Clozapine on Extracellular Dopamine Levels in the Shell Subregion of the Rat Nucleus Accumbens is Reversed Following Chronic Administration: Comparison with a Selective $5-\mathrm{HT}_{2 \mathrm{C}}$ Receptor Antagonist
}

\author{
Claire S Shilliam*,' and Lee A Dawson' \\ 'Department of Neuropharmacology, Psychiatry Centre of Excellence for Drug Discovery, GlaxoSmithKline, Harlow, UK
}

\begin{abstract}
The clinical onset of both the therapeutic and side effects of antipsychotic drugs can take days/weeks to develop. Therefore, it is likely that adaptive changes in neurotransmission of key systems may only manifest upon chronic administration. Thus, using in vivo microdialysis we have evaluated the acute and chronic (2I days) effects of the atypical antipsychotic clozapine on nucleus accumbens (NAcc) dopamine (DA) output in the rat. Clozapine ( $10 \mathrm{mg} / \mathrm{kg}$ p.o.) produced an acute $60 \%$ increase in extracellular levels of DA in the shell but not the core subregion of the NAcc. This clozapine-induced effect was also apparent on day 8 (59\% increase) of chronic administration. However, on day 22 (following 21 days chronic administration), clozapine-induced a significant decrease in extracellular DA levels (44\% decrease). Since clozapine possesses significant affinity for the $5-\mathrm{HT}_{2} \mathrm{C}$ receptor these clozapine-induced effects were compared to those of SB-2432 I3, a selective 5- $\mathrm{HT}_{2}$ receptor antagonist. SB-2432 13 (10 mg/kg p.o.) had no effect on NAcc DA levels either acutely or following 21 days chronic administration. These data demonstrate that the atypical neuroleptic clozapine is more effective at eliciting changes in the shell vs the core subregion of the NAcc. In contrast, chronic treatment produces a time-dependent reduction in clozapineinduced DA efflux in the shell subregion. This selective temporal change in dopaminergic neurotransmission may be associated with the delayed therapeutic onset of antipsychotic activity. However, since SB-243213 had no effect on DA levels in the NAcc, it is likely that $5-\mathrm{HT}_{2 \mathrm{C}}$ receptor antagonism alone is not the mechanism by which clozapine exerts is actions.
\end{abstract}

Neuropsychopharmacology (2005) 30, 372-380, advance online publication, 24 November 2004; doi: | 0. I038/sj.npp. I 30059 |

Keywords: clozapine; nucleus accumbens; dopamine; microdialysis; 5-HT2C receptors

\section{INTRODUCTION}

Chronic administration of neuroleptics or antipsychotic drugs has been the treatment of choice for schizophrenia for the last four decades. The introduction of chlorpromazine and related compounds into psychiatric practice revolutionized the pharmacotherapy of schizophrenia. Antipsychotic drugs improve positive symptoms in schizophrenia; however, it was soon discovered that these compounds also produced a variety of neurological syndromes that can occur within hours or days of onset of treatment. The neurological side effects such as acute dystonia, akathisia, and Parkinson-like syndrome were designated extrapyra-

*Correspondence: Dr CS Shilliam, Department of Neuropharmacology, Psychiatry Centre of Excellence for Drug Discovery, GlaxoSmithKline, Harlow, Essex CMI9 5AW, UK, Tel: + 441279622878 , Fax: + 441279 875389, E-mail: Claire.S.Shilliam@gsk.com

Received 26 May 2004; revised 9 September 2004; accepted 10 September 2004

Online publication: 16 September 2004 at http://www.acnp.org/citations/ Npp09| 604040247/default.pdf midal side effects (EPS) due to the involvement of the extrapyramidal system. In addition, prolonged administration (months to years) of antipsychotic drugs resulted in the development of periorial tremor and tardive dyskinesia (for a review see Baldessarini and Tarsey, 1980; Casey, 1991). Until the discovery of clozapine in the early 1970s, it was believed that therapeutic effect could not be separated from these side effects. Clozapine was the first 'atypical' antipsychotic that possessed therapeutic efficacy against the positive symptoms of schizophrenia without inducing the EPS-like side effects. Clozapine has subsequently been followed (but arguably never superceded in terms of efficacy) by a range of molecules with similar atypical like profiles, for example olanzapine, risperidone, and quetiapine.

The nucleus accumbens (NAcc), the main target of the mesotelencephalic dopamine (DA) system, has been the focus of many theories exploring the chemoarchitectural substrates of schizophrenia and affective disorders as well as theories of reward and motivation (Pontieri et al, 1995; Heidbreder et al, 1999). The existence of subterritories 
within the NAcc is widely supported by histochemical, in vivo neurochemical, electrophysiological as well as morphological and ultrastructural studies (for a review see Zahm, 2000). Specifically, the NAcc can be subdivided into a dorsolateral core and ventromedial shell. Such a structural compartmentation can be defined by the various neurochemical and cellular features of the NAcc that designate specific afferent and efferent systems, probably involved in different behavioral functions. For example, the shell responds more sensitively than the core to a variety of stimuli, including drugs of abuse (Pontieri et al, 1995; Hedou et al, 1999; Heidbreder et al, 1999), restraint and pharmacological stress (Deutch and Cameron, 1992; Horger et al, 1995; Kalivas and Duffy, 1995; King et al, 1997), food (Bassareo and Di Chiara, 1999), and novelty (Rebec et al, 1997; Rebec, 1998). The shell subregion of the NAcc may also play an important role in the mediation of the therapeutic effects of antipsychotic drugs. Several studies have shown that all antipsychotic agents increase fos protein immunoreactivity or c-fos mRNA expression in the shell, but only those drugs associated with extrapyramidal motor symptom side effects, such as haloperidol, stimulate fos expression in the core (Deutch, 1996; Hurley et al, 1996; Werme et al, 2000). Furthermore, evidence suggests that low doses of the atypical antipsychotics produce larger changes in extracellular DA levels in the shell than in the core of the NAcc (Marcus et al, 1996, 2000; Merchant and Dorsa, 1993). The ability of atypical antipsychotics to induce responses within the shell subregion is thought to be associated with their ability to preferentially affect DA neurones within the ventral tegmental area (VTA). The NAcc shell projects to the ventral pallidum, which in turn projects to the VTA, whereas the core subregion primarily connects to the dorsolateral ventral pallidum, which in turn projects to the subthalamic nucleus and the substantia nigra (Meredith et al, 1992). Acute administration of clozapine or amisulpiride increases the number of spontaneously active neurones in the VTA but not substantia nigra (Blackburn et al, 2002; Di Giovanni et al, 1998), whereas haloperidol produced a significant and equipotent increase in spontaneous firing in both VTA and substantia nigra neurones (Blackburn et al, 2002; Goldstein et al, 1993).

Several studies have shown that repeated treatment with typical antipsychotics caused a marked reduction in the number of spontaneously active dopaminergic neurones in both the VTA and substantia nigra (Bunney and Grace, 1978; Chiodo and Bunney, 1983, White and Wang, 1983). However, repeated treatment with atypical antipsychotics produced a selective reduction in dopaminergic neuronal activity in the VTA. Considering that clinical onset of both the therapeutic and side effects of antipsychotic drugs can take days or weeks to develop, it has been postulated that the time-dependent inactivation of VTA and substantia nigral DA neurones by prolonged administration of antipsychotic drugs may underlie the delayed onset of antipsychotic pharmacotherapy and tardive dyskinesia, respectively (Chiodo and Bunney, 1983; White and Wang, 1983).

The atypical antipsychotic, clozapine has a rich pharmacology that includes affinity for many receptors including dopamine $\mathrm{D}_{1}, \mathrm{D}_{2}, \mathrm{D}_{3}$, and $\mathrm{D}_{4}$ receptors, and $5-\mathrm{HT}_{1 \mathrm{~A}}, 5-$
$\mathrm{HT}_{2 \mathrm{~A}}, 5-\mathrm{HT}_{2 \mathrm{C}}$, and $5-\mathrm{HT}_{3}$ receptors (for a review see Ashby and Wang, 1996). Recent electrophysiological and microdialysis studies suggest that $5-\mathrm{HT}_{2 \mathrm{C}}$ receptor antagonists produce similar effects to those reported of clozapine treatment on VTA neuronal activity and extracellular DA levels in NAcc (Di Matteo et al, 2002a,b). Thus, it has been suggested that antagonist or inverse agonist activity at $5-\mathrm{HT}_{2 \mathrm{C}}$ receptors may underlie the clinical properties of atypical antipsychotics (Herrick-Davis et al, 2000).

The present study has investigated the effect of acute administration of clozapine on extracellular DA levels in core and shell subregions of the NAcc using in vivo microdialysis in the rat, and compared these effects to those of 5-methyl-1-[[2-[92-methyl-3-pyridyl0oxy]-5-pyridyl]carbamoyl]-6-trifluoromethylindone (SB-243213), a highly selective, brain penetrant, $5-\mathrm{HT}_{2 \mathrm{C}}$ receptor antagonist (Bromidge et al, 2000; Wood et al, 2001). Furthermore, we have investigated the effect of chronic administration of both compounds (ie clozapine or SB-243213 for 8 and 21 days) on extracellular DA levels in the shell subregion of the NAcc.

\section{MATERIALS AND METHODS}

\section{Subjects}

Two groups of 24 male Sprague-Dawley rats (Charles River UK Ltd) weighing 250-300 g were housed in groups of 4-5 per cage in a temperature and humidity controlled environment with free access to food (restricted to $20 \mathrm{~g} /$ day after surgery) and water. Rats were kept on a $12 \mathrm{~h}$ light: dark cycle with lights on at 0700 . All experimental procedures carried out in the present study were within the guidelines of the Animals (Scientific Procedures) Act 1986.

\section{Surgical Procedure}

The animals were anesthetized using a mixture of medetomidine $(0.04 \mathrm{ml} / 100 \mathrm{~g}$ s.c.) and fentanyl $(0.9 \mathrm{ml} / \mathrm{kg}$ i.p. $)$. Once deep anesthesia was obtained, rats were transferred to a stereotaxic frame (David Kopf, Topanga, CA) with the upper incisor bar set at $-3.2 \mathrm{~mm}$ below the interaural line. Rats were put on a homeothermic blanket set at $37^{\circ} \mathrm{C}$ throughout. An incision was made to reveal bregma, from which all coordinates were taken. Holes were then drilled for four anchor screws, and another for unilateral placement of an intracerebral guide cannula (CMA 11, Biotech, UK) into the shell (12 acute, 24 chronic) or core (12 acute) subregions of the NAcc. The coordinates with respect to bregma were as follows (Paxinos and Watson, 1986): for the shell of the NAcc: $+1.2 \mathrm{~mm}$ anterior (A) to bregma; $0.8 \mathrm{~mm}$ lateral $(\mathrm{L})$ to the midsagittal sinus; $5.8 \mathrm{~mm}$ ventral $(\mathrm{V})$ to the dura surface; for the core of the NAcc: $A=+1.2 \mathrm{~mm}$, $\mathrm{L}=2.0 \mathrm{~mm}, \mathrm{~V}=5.8 \mathrm{~mm}$. The dura directly beneath the guide was broken, and the guide was implanted. Using dental cement, the guide and a tether screw (Presearch Limited, UK) placed posterior to the guide were secured in place, and the wound was sealed. Anesthesia was reversed using a mixture of atipamezole $(0.02 \mathrm{ml} / 100 \mathrm{~g}$ s.c. $)$ and nalbuphine $(0.02 \mathrm{ml} / 100 \mathrm{~g}$ s.c. $)$. The rats were monitored until they regained their righting reflex. The animals were 
allowed to recover for 1 week before the microdialysis experiment started.

\section{Chronic Dosing Protocol}

All animals were treated once daily (between 1000 and 2400) for 22 days with either clozapine (Tocris, UK; $10 \mathrm{mg} / \mathrm{kg}$ ), SB-243213 (10 mg/kg), or vehicle ( $1 \%$ methyl cellulose, $2.5 \%$ BRIJ 35 (Polyoxyethylene 23 lauryl ether-Sigma, Poole, UK)) orally by gastric gavage $(2 \mathrm{ml} / \mathrm{kg})$. The $1 \mathrm{st}, 8 \mathrm{th}$, and 22nd doses were administered during the course of the microdialysis experiment after collection of basal samples as indicated by the experimental protocol. In total, $18 \mathrm{~h}$ prior to the start of experimentation, the animals were randomly assigned to one of six circular polycarbonate microdialysis cages ( $\varnothing 285 \mathrm{~mm} ; \mathrm{H}: 355 \mathrm{~mm}$ ) and left to habituate to their new environment.

\section{In Vivo Microdialysis Procedure}

Before implantation, microdialysis probes (CMA/11, $2 \mathrm{~mm}$ active cuprophane membrane length, Biotech, UK) were placed in $70 \%$ ethanol, and perfused at $2-5 \mu \mathrm{l} / \mathrm{min}$ with artificial cerebrospinal fluid (aCSF) containing $125 \mathrm{mM}$ $\mathrm{NaCl}, \quad 2.5 \mathrm{mM} \quad \mathrm{KCl}, \quad 1.18 \mathrm{mM} \quad \mathrm{MgCl}_{2} \cdot 6 \mathrm{H}_{2} \mathrm{O}, \quad 1.26 \mathrm{mM}$ $\mathrm{CaCl}_{2} \cdot 2 \mathrm{H}_{2} \mathrm{O}$, and $2.0 \mathrm{mM} \mathrm{Na} \mathrm{NPO}_{4}$, adjusted to $\mathrm{pH} 7.4$ with $85 \% \mathrm{H}_{3} \mathrm{PO}_{4}$ (HPLC grade). Both probe inlet and outlet tubing were attached to a dual quartz lined two-channel liquid swivel (Instech 375/D/22QE, Presearch Ltd, Hitchin, UK) on a low mass spring counterbalanced arm, which in turn was connected to a gas tight syringe (CMA Exmire $1 \mathrm{ml}$, Biotech, UK) on a microinfusion pump (Univentor 864 , Biotech, UK). Probes were perfused at $1 \mu \mathrm{l} / \mathrm{min}$ for $2 \mathrm{~h}$ before sample collection. After this equilibration period, three basal samples were collected at 30-min intervals, before animals were administered with clozapine $(10 \mathrm{mg} / \mathrm{kg}$ p.o.) or SB-243213 (3 and $10 \mathrm{mg} / \mathrm{kg}$, p.o. in acute study, $10 \mathrm{mg} / \mathrm{kg}$ p.o. in chronic study). Microdialysate samples were collected into glass vials (Chromacol Ltd, UK) containing $5 \mu \mathrm{l} 0.3 \%$ acetic acid for an additional 240-min period. All microdialysate samples were subsequently analyzed for DA content using high-performance liquid chromatography (HPLC). Following the microdialysis experiment, probes were removed, the guide pin was replaced and animals were returned to their home cages. Animals in acute studies were allowed 7 days recovery between uses and subsequent treatment was allocated according to a randomized crossover design that ensured that no animal was used more than three times or received the same treatment twice. Animals in the chronic study were tested in further microdialysis experiments on days 8 and 22 of treatment.

\section{Chromatographic Analysis of Brain Microdialysates (HPLC-ECD)}

Chromatographic separations were performed using a Capcell PAK, Strong Cation Exchange column $(5 \mu \mathrm{m}$ UG80, $1.5 \times 150 \mathrm{~mm}^{2}$; Shiseido, Japan). The mobile phase consisted of (mM) $13 \mathrm{Na}_{2} \mathrm{HPO}_{4}, 87 \mathrm{NaH}_{2} \mathrm{PO}_{4}, 0.1$ EDTA, 5 $\mathrm{NaCl}$, and $20 \%$ methanol buffered to $\mathrm{pH} 6.0$, and was delivered via a Jasco PU-980 HPLC pump (Jasco, Tokyo,
Japan) at a flow rate of $0.2 \mathrm{ml} / \mathrm{min}$ at a temperature of $40^{\circ} \mathrm{C}$. DA was detected via an electrochemical amperometric detector (Decade, Antec-Leyden, Netherlands) fitted with a $3 \mathrm{~mm}$ glassy carbon electrode (VT-03, Antec-Leyden, Netherlands) with a working electrode set at $+500 \mathrm{mV} v \mathrm{~s}$ $\mathrm{Ag} / \mathrm{AgCl}$ reference. The analog data output was smoothed at $40 \mathrm{~Hz}$ before collection (LINK, Antec-Leyden, Netherlands). All data were acquired on a PC using Millennium32 software (Waters, Milford, MA, USA). Samples $(10 \mu \mathrm{l})$ were injected via a cooled $\left(4^{\circ} \mathrm{C}\right)$ Gilson model 234 autosampler (Gilson, Villiers-le-Bel, France) fitted with a six port rotary valve (Model 7125, Rheodyne, Berkley, CA, USA) with a $20 \mu$ injection loop.

\section{Histology}

At the end of the study rats were killed and brains were removed and stored in $4 \%$ paraformaldehyde solution for a minimum of 7 days. Coronal sections $(50 \mu \mathrm{m})$ were cut using a cryostat microtome and probe placement was verified. Data from animals with incorrect probe placement were removed from further analysis.

\section{Drug Treatments}

Clozapine was purchased from Tocris Cookson (Bristol, UK). SB-243213-A (5-methyl-1-[[2-[92-methyl-3-pyridy10oxy]-5-pyridyl]carbamoyl]-6-trifluoromethylindone hydrochloride) was synthesized by Medicinal Chemistry, GlaxoSmithKline (Harlow, UK). Clozapine and SB-243213 were ground with one drop (20-30 $\mu$ l) BRIJ-35 (Sigma, Poole, Dorset, UK) and suspended in $1 \%$ methylcellulose in water, and dosed periorally (p.o.) at a dose volume of $2 \mathrm{ml} /$ $\mathrm{kg}$. Doses of SB-243213-A were chosen based on the robust effects observed in behavioral and electrophysiological studies (Wood et al, 2001; Blackburn et al, 2002). Dose of clozapine $(10 \mathrm{mg} / \mathrm{kg})$ was chosen based on previous in house studies showing robust effects on DA levels in other regions of the brain. Reasonable $5-\mathrm{HT}_{2 \mathrm{C}}$ receptor occupancy at this dose was concluded based on evidences of Di Matteo et al (2002a).

\section{Data Analysis}

All data were expressed as percentage of baseline control levels. The average concentration of three stable baseline samples was determined and defined as $100 \%$. Total DA efflux was calculated using the trapezoid rule for determination of area under the curve (AUC). Data were analyzed using repeated measures analysis of variance (ANOVA), followed by post hoc Fishers least significant difference test where appropriate. The level of significance was set at $P<0.05$.

\section{RESULTS}

Effects of Acute Clozapine (10 mg/kg p.o.) or SB-243213 ( 3 and $10 \mathrm{mg} / \mathrm{kg}$ p.o.) on Extracellular Levels of DA in the Subregions of the Rat NAcc

Figure 1 shows (a) schematic representation of the target probe placement and photomicrograph of the probe tracts 
a

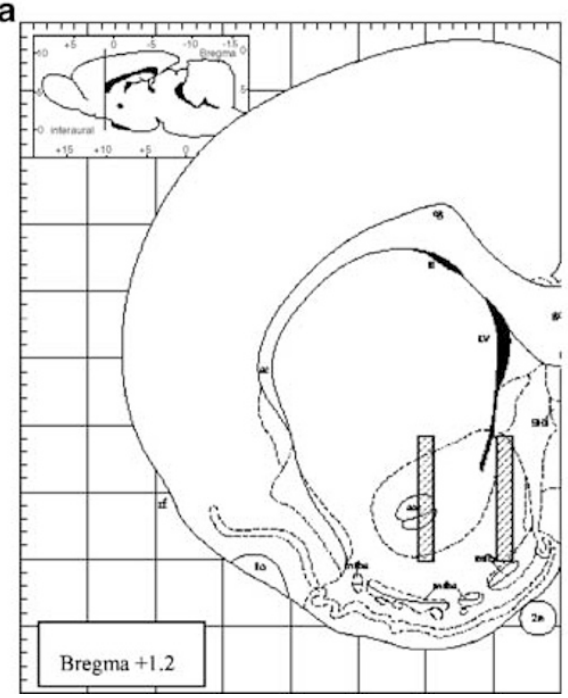

b

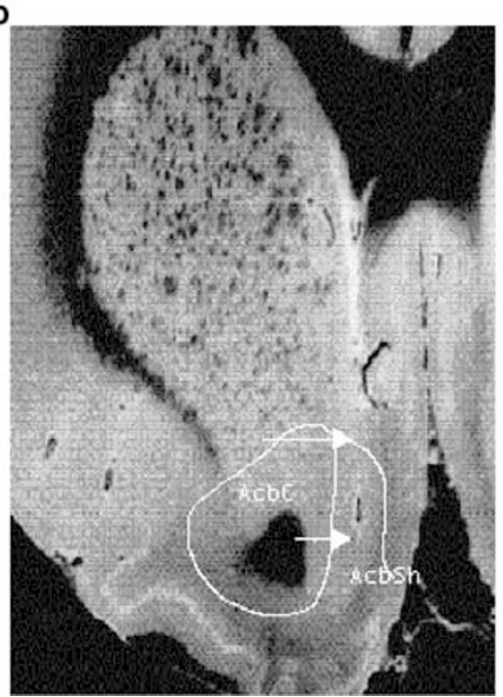

c

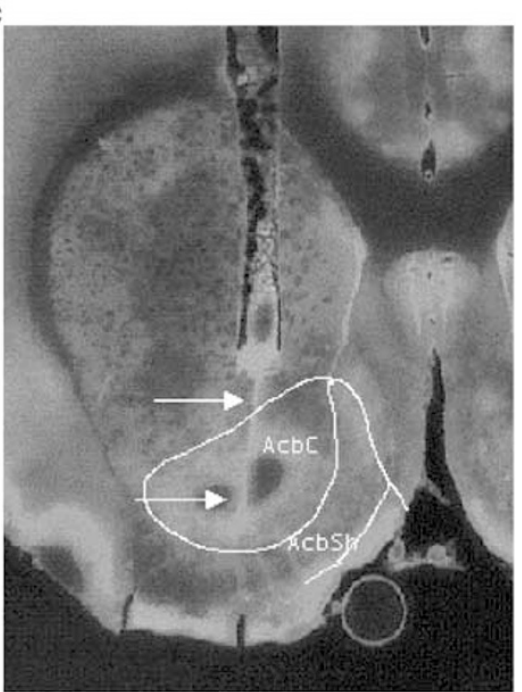

Figure I Schematic of the target probe placement (a) and photomicrographs of the probe tracts in the (b) shell and (c) core of the nucleus accumbens. Shaded area shows relative size of microdialysis probe.

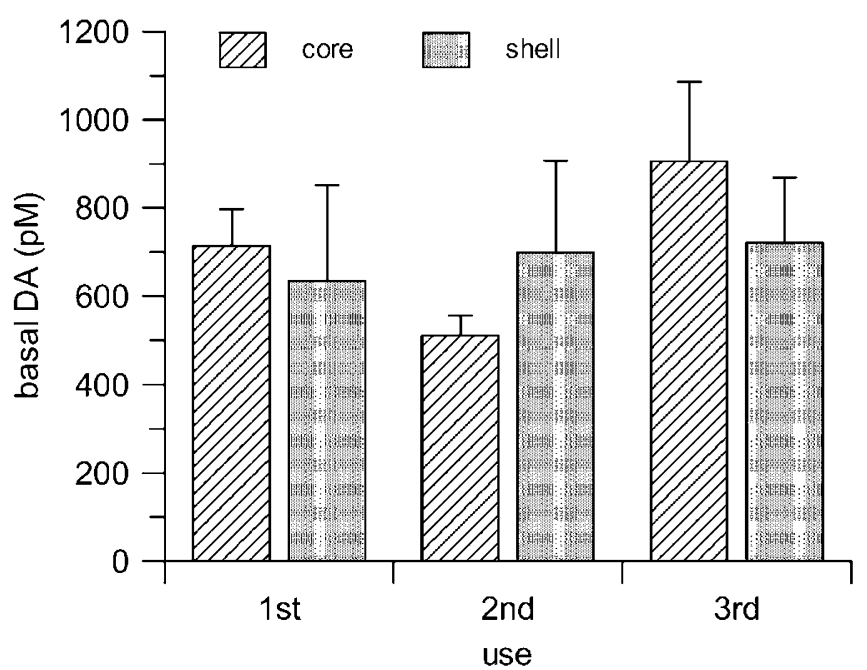

Figure 2 Basal levels of DA in shell and core subregions after repeated uses within the crossover design. Data are expressed as mean $( \pm \mathrm{SEM}$; $n=5-7)$ concentration of DA (pM).

in the (b) shell and (c) core of the NAcc. Basal levels of DA within the acute study were not affected by repeated use within the crossover design (Figure 2). In addition, no difference in basal DA levels was observed between NAcc subregions.

Acute clozapine administration produced no effect on DA levels within the core subregion of the NAcc (Figure 3). In contrast, extracellular levels of DA in the shell subregion were significantly increased by administration of clozapine to a maximum value of $160 \pm 22 \%$ of preinjection basal levels $\left(\mathrm{F}_{1,7}=6.71, P<0.05\right.$ compared to vehicle). Post hoc analysis revealed that there was a significant dose $\times$ region effect $\left(\mathrm{F}_{1,18}=4.406, P<0.05\right)$. In contrast, treatment with doses of SB-243213, which have previously been shown to be effective in behavioral models (Wood et al, 2001), produced no change in DA levels in either subregion (Figure 4).
Effects of Chronic Clozapine (10 mg/kg p.o, o.d.) or SB-243213 (10 mg/kg p.o., o.d.) on Extracellular Levels of DA in the Shell of the Rat NAcc

Chronic treatment with either clozapine or SB-243213 for 7 or 21 days did not affect basal levels of DA (Figure 5). As previously seen, in the acute subregion comparison, a clozapine challenge to drug naïve animals produced a significant increase in extracellular DA levels in the shell of the NAcc ( $\max 188 \pm 43 \% \mathrm{~F}_{1,11}=5.185, P=0.0438$; Figure 6). Similarly, a clozapine challenge to animals on day 8 of chronic clozapine treatment produced a $159 \pm 21 \%$ increase in extracellular DA levels in the shell. This increase failed to reach statistical significance compared to vehicle but was not significantly different from the day 1 response. In contrast, a challenge with clozapine, following 21 days chronic administration (ie on day 22), produced a significant reduction in extracellular DA levels compared to chronic vehicle treated animals reaching a maximum effect of only $56 \%$ of preinjection basal levels $\left(\mathrm{F}_{1,10}=8.499\right.$, $P=0.0154)$. This was also significantly different to the response observed after challenges on days 1 and 8 $\left(\mathrm{F}_{1,11}=8.794, P=0.0128 ;\right.$ and $\mathrm{F}_{1,10}=12.707, P=0.0051$, respectively). Overall analysis of chronic clozapine treatment $v s$ time revealed a significant temporal effect of clozapine $\left(\mathrm{F}_{2,112}=5.54, P<0.05\right)$.

In contrast, a challenge dose of SB-243213 $(10 \mathrm{mg} / \mathrm{kg})$ following 7 and 21 days of chronic administration produced no change in extracellular DA levels in the shell subregion of the NAcc (Figure 7).

\section{DISCUSSION}

The present study aimed to investigate the effect of the atypical antipsychotic clozapine on extracellular levels of $\mathrm{DA}$ in the shell and core subregions of the NAcc as measured by microdialysis in the rat and subsequently, whether the acute responses observed were altered following chronic administration. Furthermore, to test whether 

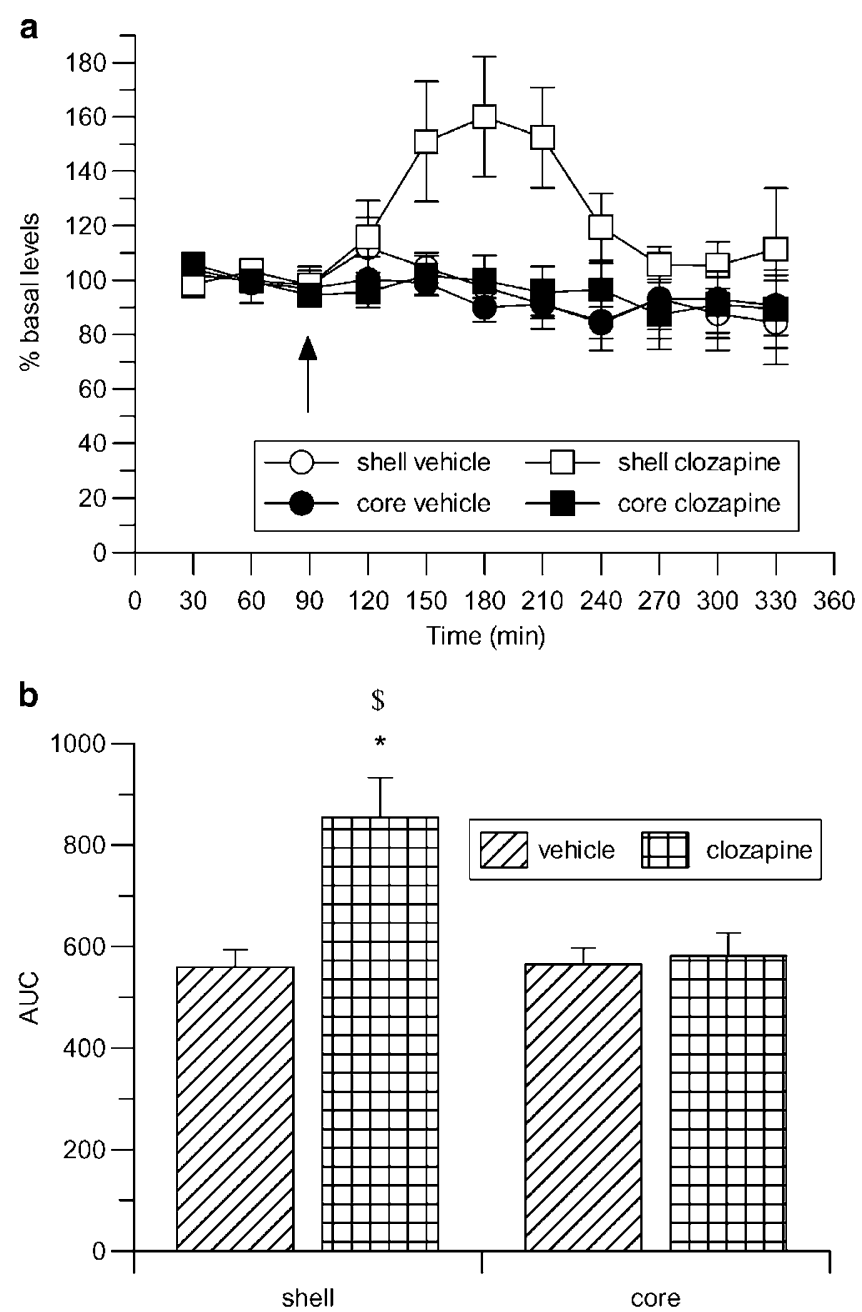

Figure 3 Effect of acute clozapine treatment $(10 \mathrm{mg} / \mathrm{kg}$, p.o.) on DA levels in core and shell subregions of the rat nucleus accumbens. Figures on the left show data expressed as mean ( \pm SEM; $n=6-8$ ) percent baseline DA and each data point represents microdialysate sampling over a $30-\mathrm{min}$ period. Arrow indicates when drug was administered. Figures on the right show total DA efflux calculated as area under the curve (AUC). An overall ANOVA revealed a significant increase in both \% basal DA levels $\left(F_{1,7}=5.535, P<0.05\right)$ and total DA efflux $\left(F_{1,7}=7.195, P<0.05\right)$ after clozapine treatment in the shell subregion. This significant effect of clozapine was found to be region specific $\left(F_{1,18}=4.406, P=0.05\right.$; AUC $\left.F_{1.18}=4.809, P<0.05\right)$. $* P<0.05$ in comparison to vehicle; $\$ P<0.05$ in comparison to core.

the $5-\mathrm{HT}_{2 \mathrm{C}}$ receptor affinity of the atypical antipsychotic contributed to the effects observed the clozapine-induced responses were compared to those of the selective $5-\mathrm{HT}_{2 \mathrm{C}}$ receptor antagonist, SB-243213. Acute clozapine $(10 \mathrm{mg} / \mathrm{kg}$ p.o.) produced a selective increase in extracellular DA levels in the shell subregion of the NAcc only. However, chronic administration resulted in a time-dependent reversal of the acute effects of clozapine producing a $40 \%$ decrease in extracellular DA levels in response to a clozapine challenge on day 22. In contrast, SB-243213 had no effect on extracellular DA levels in either subregion of the NAcc after acute dosing or in the shell subregion following 21 days chronic administration.

Many microdialysis studies have demonstrated that an acute challenge with clozapine produces a significant
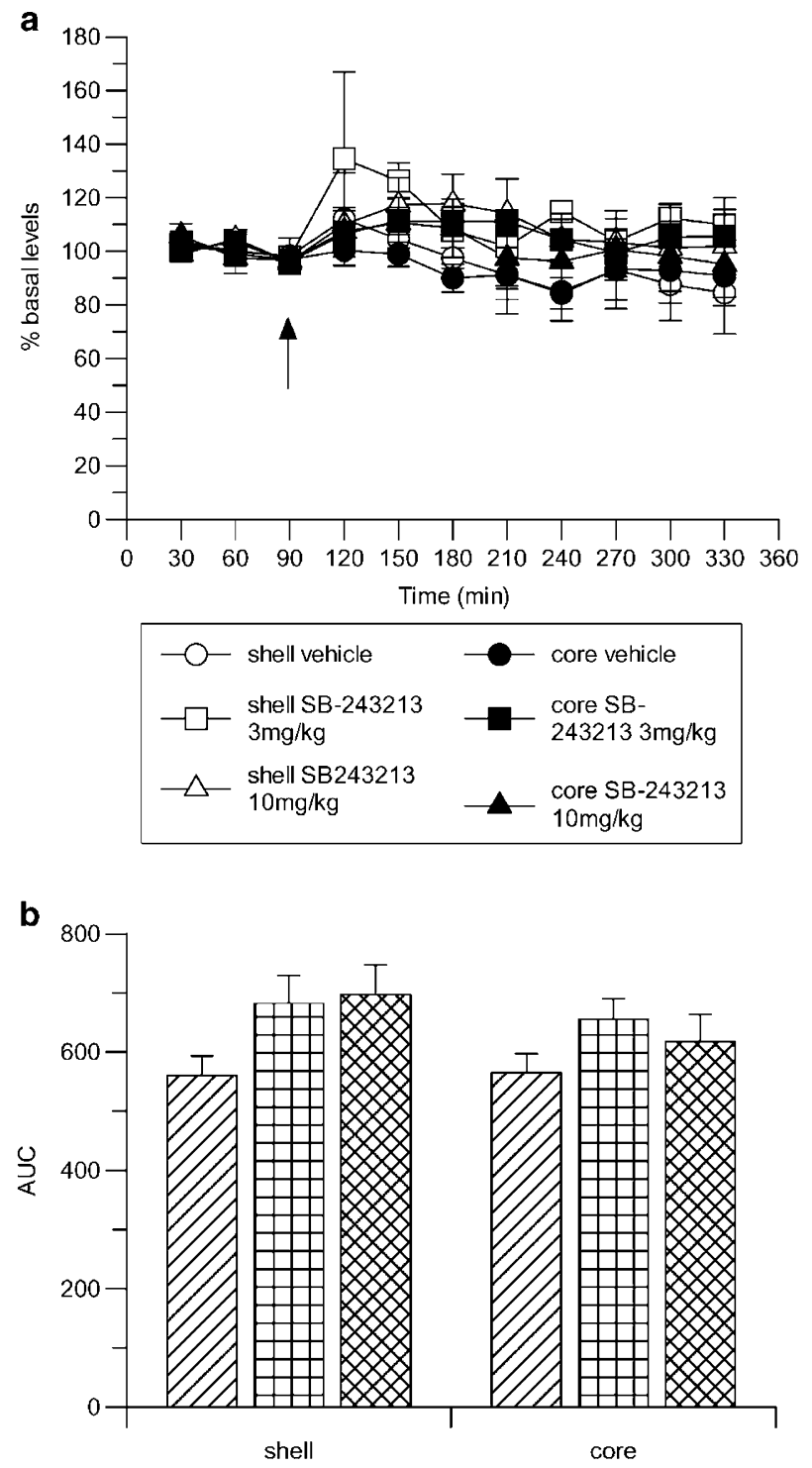

$\square$ vehicle $\mathbb{Z}$ SB-2432133mg SB-24321310mg

Figure 4 Effect of acute SB-243213 treatment (3, or $10 \mathrm{mg} / \mathrm{kg}$, p.o.) on $\mathrm{DA}$ levels in core and shell subregions of the rat nucleus accumbens. Figures on the left show data expressed as mean ( \pm SEM; $n=6-8)$ percent baseline dopamine and each data point represents microdialysate sampling over a 30-min period. Arrow indicates when drug was administered. Figures on the right show total DA efflux calculated as area under the curve (AUC). No significant effects of SB-2432 I 3 on DA levels were observed in either subregion.

increase in extracellular DA in the rat NAcc (Ichikawa and Meltzer, 1990; Hernandez and Hoebel, 1995; Nomikos et al, 1994). However, a specific differential subregion effect has not previously been shown using this methodology. The present data agree with the findings from in vivo voltammetric studies (Marcus et al, 1996, 2000) showing that low doses of clozapine, and other atypical antipsychotics (ie risperidone, sertindole and quetiapine), that exhibit lower levels of occupancy of $\mathrm{DA} \mathrm{D}_{2}$ receptors, elicit greater changes in DA concentrations in the shell compared with the core region of the NAcc. In contrast, typical neuroleptics 


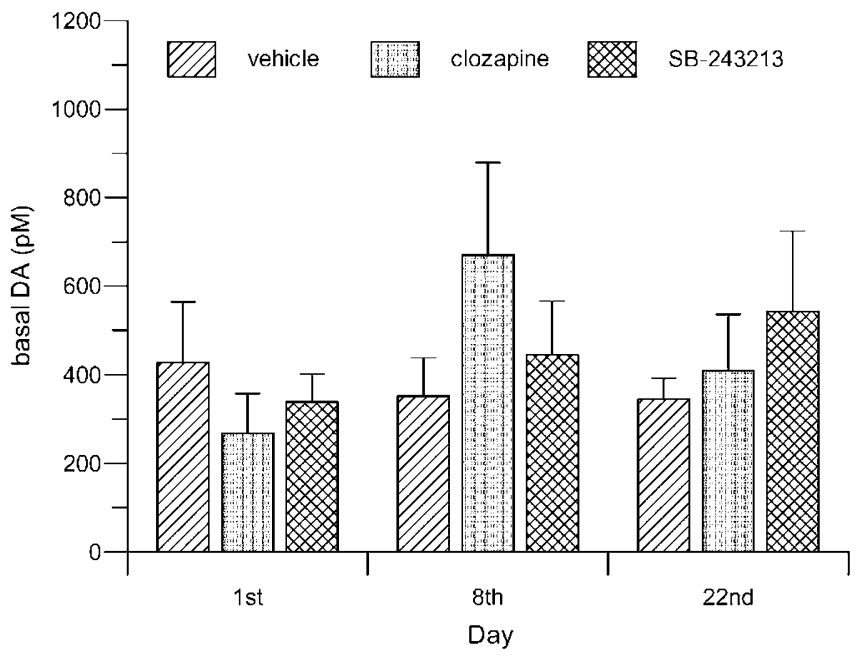

Figure 5 Basal levels of DA in the shell subregion of nucleus accumbens in naïve rats and prior to challenge after treatment with either vehicle or clozapine ( $10 \mathrm{mg} / \mathrm{kg}$, p.o., o.d.) for 7 and 21 days. Data are expressed as mean ( \pm SEM; $n=6-8$ ) concentration of DA (pM).

such as haloperidol and raclopride, which are characterized by potent $\mathrm{DA} \mathrm{D}_{2}$ receptor antagonism, produce larger or similar modifications in DA levels in the core versus the shell subregions (Marcus et al, 1996).

A clozapine challenge to animals that had received 21 days treatment prior to the microdialysis study produced a significant reduction in extracellular DA levels that was maintained for the duration of the sampling period. Reduction in DA neuronal activity, known as depolarization block, after chronic administration of antipsychotic drugs has been demonstrated using electrophysiological techniques (for a review see Grace et al, 1997). Typical antipsychotics, such as haloperidol and chlorpromazine, produce an increase in neuronal firing upon acute challenge but a subsequent decrease in the activity of spontaneously active DA cells in both substantia nigra and ventral tegmental regions following chronic treatment (Bunney and Grace, 1978; White and Wang, 1983; Di Giovanni et al, 1998). In contrast, chronic administration of the atypical antipsychotics clozapine, thioridazine, molindone, and sulpiride produced a selective reduction in firing in the VTA and exhibited no, or limited effects, in the substantia nigra (Blackburn et al, 2002; Di Giovanni et al, 1998; Skarsfeldt, 1988; White and Wang, 1983). This timedependent inactivation of ventral tegmental and substantia nigra DA neurones by prolonged administration of antipsychotic drugs has been suggested to relate to the delayed onset of antipsychotic efficacy and EPS like side effects (eg tardive dyskinesia) respectively (White and Wang, 1983).

Previous attempts to measure the impact of depolarization block on indices of DA release have failed to yield consistent results. Thus, reports from microdialysis studies investigating the effects of chronic clozapine on basal DA levels in the NAcc are mixed. The data from the present study agree with a number of studies reporting that basal DA levels in the NAcc are not altered by chronic clozapine administration (Ichikawa and Meltzer, 1990; Invernizzi et al,
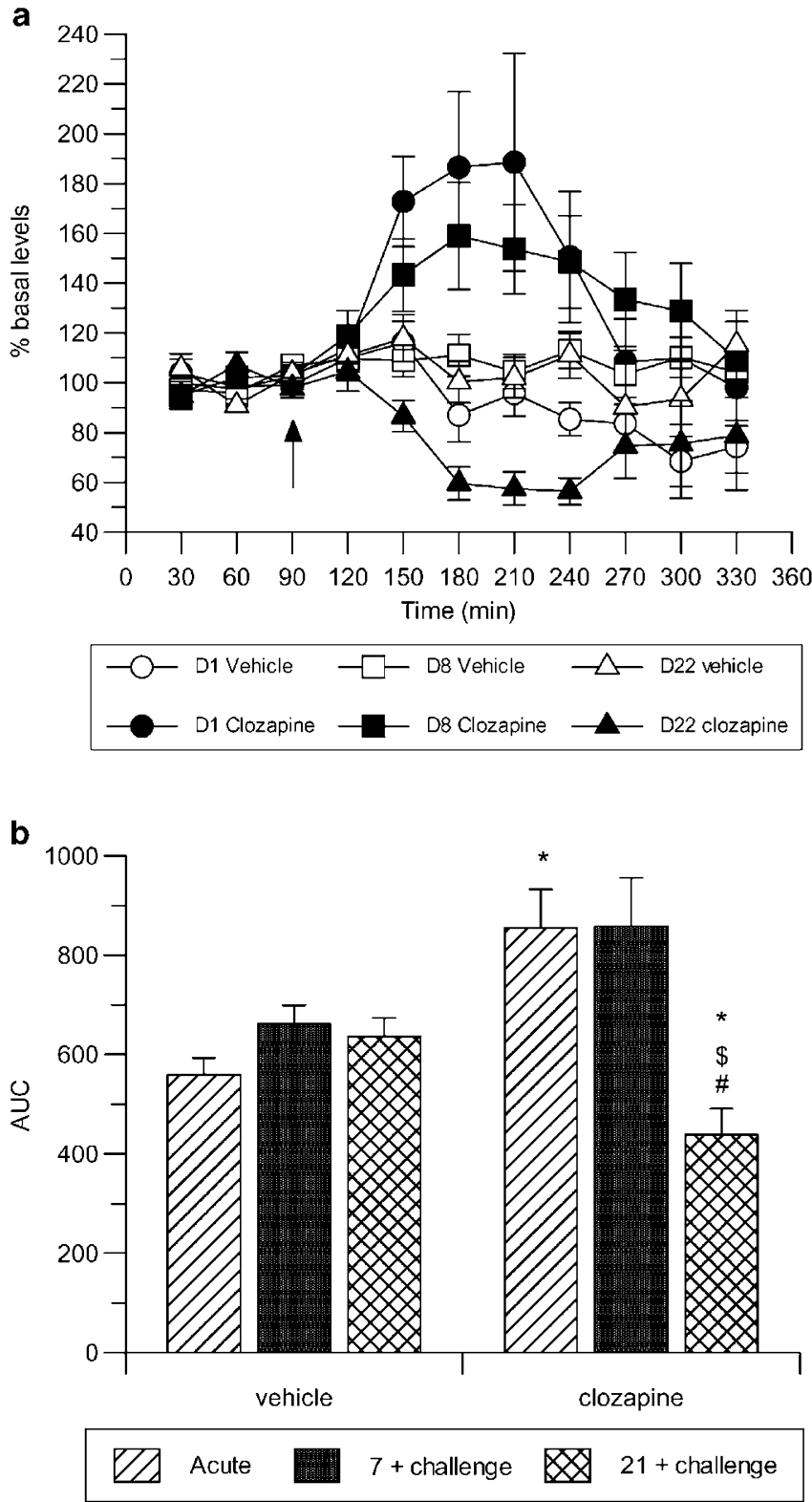

Figure 6 Effect of a challenge dose of clozapine following 1, 8, and 21 days of chronic treatment with clozapine $(10 \mathrm{mg} / \mathrm{kg}$, p.o., o.d.) on extracellular DA levels in the shell subregion of the rat nucleus accumbens. Figures on the left show data expressed as mean $( \pm$ SEM; $n=6-8)$ percent baseline DA and each data point represents microdialysate sampling over a 30-min period. Arrow indicates when drug was administered. Analysis of the effect of chronic treatment revealed a significant effect of treatment duration $\left(F_{2,112}=5.54 ; P<0.05\right)$. Challenge with clozapine following 21 days chronic administration (ie on day 22) produced a significant reduction in DA levels (compared to vehicle challenge after chronic vehicle treatment) to $56 \%$ of basal levels $\left(F_{1,10}=8.499, P<0.05\right)$ that was significantly different to the response observed after challenges acutely and on day $8 \quad\left(F_{1,11}=8.794, P=0.0128 ;\right.$ and $F_{1,10}=12.707, P=0.005 \mathrm{I}$, respectively). Figures on the right show total DA efflux calculated as area under the curve (AUC). Total DA efflux was significantly increased by clozapine after acute treatment $\left(F_{1,11}=5.431, P<0.05\right)$ and significantly reduced after challenge on day $22\left(F_{1,10}=9.686, P<0.05\right.$ vs vehicle; $F_{1,11}=9.41, P<0.01$ vs acute; $F_{1,10}=14.285, P<0.01$ vs day 8$)$. $* P<0.05$ in comparison to vehicle; $\$ P<0.05$ in comparison to acute treatment; $\# P<0.01$ in comparison to day 8 . 

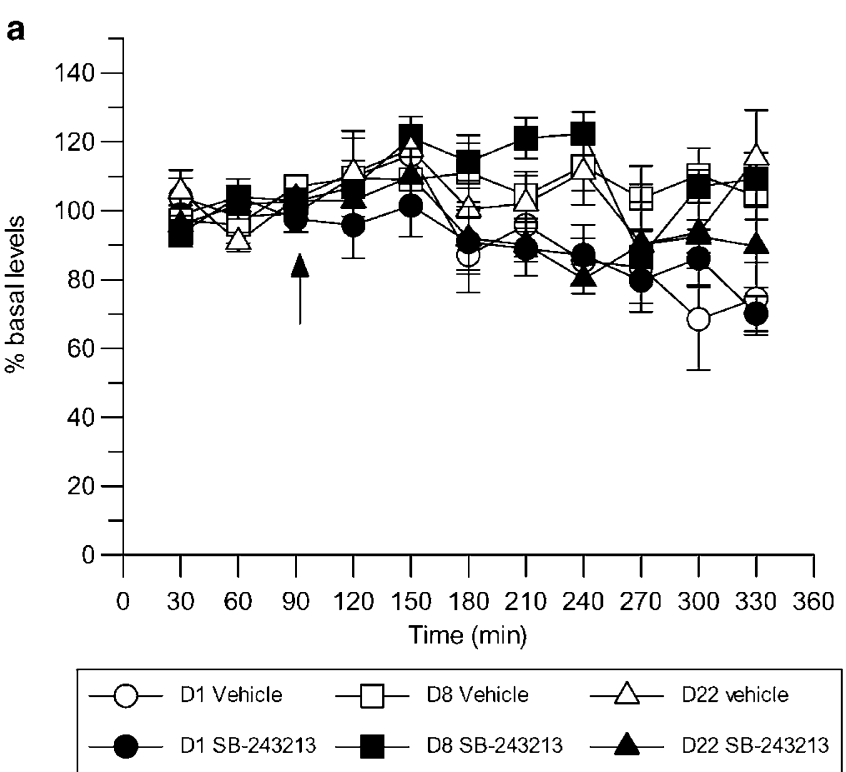

b

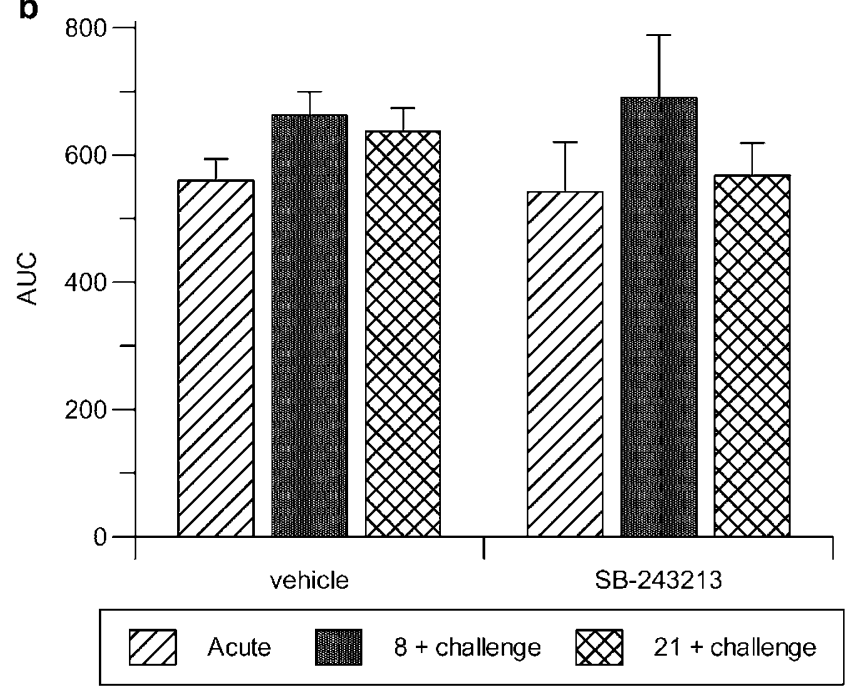

Figure 7 Effect of a challenge dose of SB-243213 following I, 8, and 21 days chronic treatment with SB-243213 (10 mg/kg, p.o., o.d.) on extracellular DA levels in the shell subregion of the rat nucleus accumbens. Figures on the left show data expressed as mean ( \pm SEM; $n=6-8)$ percent baseline DA and each data point represents microdialysate sampling over a 30-min period. Arrows indicate when drug was administered. Figures on the right show total DA efflux calculated as area under the curve (AUC). No significant effects of acute dosing or following chronic treatment with SB-243213 were observed.

1995), while others report a significant decrease (Chen $e t$ al, 1991). The lack of an effect on basal levels of DA in microdialysis studies is not necessarily indicative of a lack of depolarization block. Many studies have shown that the dopaminergic system displays remarkable adaptability following manipulations that alter DA function. Evidence suggests that as many as $55 \%$ of the remaining active dopaminergic neurones fire in an irregular bursting pattern following chronic clozapine treatment (White and Wang, 1983). In addition, in vivo data have shown that dopaminergic cells firing in a bursting pattern can release up to six times more DA than those firing in a nonbursting mode
(Gonon, 1988). Therefore, although some studies have shown a reduction in basal DA levels following the induction of depolarization block (Chen et al, 1991; Moore et al, 1998), it is possible that depolarization block may have occurred irrespective of whether there is evidence of a reduction in basal DA levels.

A direct comparison of these data with those of other investigators should be interpreted with care as caveats associated with differences in probe placement (ie stereotaxic coordinates), microdialysis techniques, and drug administration can all impact the on data generated. In addition, it has been suggested that the insertion of the probe shortly after implantation surgery into either the NAcc or the striatum may lesion feedback pathways and subsequently reverse the antipsychotic drug-induced effects (Grace, 1992). However, there is evidence that depolarization block can be observed using acute implantation of microdialysis probes. Thus, Chen et al (1991) showed a reduction in DA levels in the NAcc after chronic clozapine treatment that could be reversed by apomorphine in animals implanted with the probe $6 \mathrm{~h}$ after the last dose of clozapine. It has also been shown that although acute implantation of the probe can reverse haloperidol-induced depolarization block in the substantia nigra, chronic guide implantation prior to depolarization block with probe insertion 2-3 h prior to the study allowed reinstatement of this block (Moore et al, 1998). As the present study was conducted using a chronic implantation protocol, it is possible that the reduction in DA levels observed in the present study, following a clozapine challenge to chronic clozapine treated animals, was as a consequence of VTA depolarization block.

As previously discussed the ability of atypical antipsychotics to induce responses within the shell subregion is thought to be associated with their ability to preferentially affect DA neurones within the VTA. Indeed, clozapine, olanzapine, and amisulpiride have been shown to exhibit selective activity on VTA neurones at doses that produce no significant effect on substantia nigra neurones (Blackburn et al, 2002; Di Giovanni et al, 1998; Stockton and Rasmussen, 1996). However, the specific pharamacological characteristic of the atypical antipsychotic, which leads to this selective effect, is not clearly understood, as all current drugs have a rich pharmacological profile. Since in vivo electrophysiological data have demonstrated that clozapine behaves in a similar manner to a $5-\mathrm{HT}_{2 \mathrm{C}}$ receptor antagonist (Blackburn et al, 2002), and clozapine has significant affinity for this receptor, the apparent selective action of clozapine on the activity of VTA neurones may be due to its affinity for $5-\mathrm{HT}_{2 \mathrm{C}}$ receptors (Arnt and Skarsfeldt, 1998). High levels of both $5-\mathrm{HT}_{2 \mathrm{~A}}$ and $5-\mathrm{HT}_{2 \mathrm{C}}$ receptor binding sites and corresponding mRNA are present in several forebrain areas including basal ganglia and limbic structures (Pazos and Palacios, 1985). While moderate levels of both $5-\mathrm{HT}_{2 \mathrm{~A}}$ and $5-\mathrm{HT}_{2 \mathrm{C}}$ receptor mRNA are found in the substantia nigra, the VTA contains predominantly $5-\mathrm{HT}_{2 \mathrm{C}}$ receptor mRNA (Eberle-Wang et al, 1997). However, in the present study, acute treatment with the selective $5-\mathrm{HT}_{2 \mathrm{C}}$ receptor antagonist SB-243213 produced no changes in DA levels in either shell or core subregion of the NAcc. This is in disagreement with a previous study, which demonstrated that the selective $5-\mathrm{HT}_{2 \mathrm{C}}$ receptor antagonist SB-242084 
increased DA levels in the NAcc (Di Matteo et al, 2002b). However, the coordinates used suggest differences in probe placement that, as demonstrated by the clozapine data, can markedly affect the observed result, and therefore a direct comparison between studies is difficult. Chronic administration and subsequent challenge with SB-243213 also had no effect on levels of DA in the NAcc shell. This lack of effect after challenge treatment was somewhat unexpected due to reported electrophysiological data showing a reduction in VTA cell firing following treatment with SB243213 that was similar to that seen with clozapine (Blackburn et al, 2002). The reason for this disparity is not entirely clear since the decrease in clozapine-induced VTA firing does appear to result in reductions in clozapineinduced DA efflux. Interestingly, the reduction in spontaneously active cells after SB-243213 treatment was not reversed by apomorphine treatment, suggesting that a direct depolarization block is possibly not mediating this effect (Blackburn et al, 2002). However, perhaps the simplest explanation is that the 5-HT2C receptor, under these experiemental conditions, is playing little role in regulating tonic DA efflux, and hence the effects of clozapine in the present study are not mediated solely by the $5-\mathrm{HT}_{2 \mathrm{C}}$ receptor.

In summary, the present study demonstrates, for the first time, using in vivo microdialysis that an acute challenge of the atypical antipsychotic, clozapine, produces a subregion dependent increase in extracellular DA levels in the shell of the rat NAcc, which is reversed following a period of chronic administration. These findings agree with electrophysiological findings, which demonstrate that clozapine has a preferential action on the mesolimbic projection pathway through a selective action on VTA DA neurones. This temporal delay may be associated with the delayed therapeutic onset of antipsychotic activity. In addition, from these data it would appear that the selectivity of action on the shell subregion and attenuation of activity following chronic administration do not appear to be mediated solely through $5-\mathrm{HT}_{2 \mathrm{C}}$ receptors, as neither acute nor chronic treatment with the selective antagonist SB-243213 produced any changes in extracellular levels of DA in the rat NAcc.

\section{REFERENCES}

Arnt J, Skarsfeldt T (1998). Do novel antipsychotics have similar pharmacological characteristics? A review of the evidence. Neuropsychopharmacology 18: 63-101.

Ashby Jr CR, Wang RY (1996). Pharmacological actions of the atypical antipsychotic drug clozapine: a review. Synapse 24: 349-394.

Baldessarini RJ, Tarsey D (1980). Dopamine and the pathophysiology of dyskinesias induced by antipsychotic drugs. Ann Rev Neurosci 3: 23-41.

Bassareo V, Di Chiara G (1999). Differential responsiveness of dopamine transmission to food-stimuli in nucleus accumbens shell/core compartments. Neuroscience 89: 637-641.

Blackburn TP, Minabe Y, Middlemiss DN, Shirayama Y, Hashimoto K, Ashby Jr CR (2002). Effect of acute and chronic administration of the selective 5-HT2C receptor antagonist SB243213 on midbrain dopamine neurons in the rat: an in vivo extracellular single cell study. Synapse 46: 129-139.

Bromidge SM, Dabbs S, Davies DT, Davies S, Duckworth DM, Forbes IT et al (2000). Biarylcarbomolindones are novel and selective 5-HT(2C) receptor inverse agonists: identification of 5-methyl-1-[[2-[92-methyl-3-pyridyl0oxy]-5-pyridyl]carbamoyl]-6trifluoromethylindone (SB-243213) as a potential antidepressant/anxiolytic agent. J Med Chem 43: 1123-1134.

Bunney BS, Grace AA (1978). Acute and chronic haloperidol treatment: comparison of effects on nigral dopaminergic cell activity. Life Sci 23: 1715-1728.

Casey DE (1991). Neuroleptic drug induced extrapyramindal syndromes and tardive dyskinesia. Schizophr Res 4: 109-121.

Chen J, Paredes W, Gardner EL (1991). Chronic treatment with clozapine selectively decreases basal dopamine release in nucleus accumbens but not in caudate-putamen as measured in vivo by brain microdialysis: further evidence for depolarization block. Neurosci Lett 122: 127-131.

Chiodo LA, Bunney BS (1983). Typical and atypical antipsychotics: differential effects of chronic administration the activity of A9 and A10 midbrain dopaminergic neurones. $J$ Neurosci 3: 1607-1619.

Deutch AY (1996). Sites and mechanisms of action of antipsychotic drugs as revealed by immediate-early gene expression. In: Csernansky JG (ed). Antipsychotics, Handbook of Experimental Pharmacology. Springer: Berlin, 120 pp 117-161.

Deutch AY, Cameron DS (1992). Pharmacological characterisation of dopamine systems in the nucleus accumbens core and shell. Neuroscience 46: 49-56.

Di Giovanni G, Di Mascio M, Di Matteo V, Esposito E (1998). Effects of acute and repeated administration of amisulpiride, a dopamine $\mathrm{D}_{2} / \mathrm{D}_{3}$ receptor antagonist, on the electrical activity of midbrain dopaminergic neurones. J Pharmacol Exp Ther 287: 51-57.

Di Matteo V, Cacchio M, Di Giulio C, Di Giovanni G, Esposito E (2002a). Biochemical evidence that the atypical antipsychotic drugs clozapine and risperidone block 5-HT2C receptors in vivo. Pharmacol Biochem Behav 71: 607-613.

Di Matteo V, Cacchio M, Di Giulio C, Esposito E (2002b). Role of serotonin2C receptors in the control of brain dopaminergic function. Pharmacol Biochem Behav 71: 727-734.

Eberle-Wang K, Mikeladze Z, Uryu K, Chesselet M-F (1997). Pattern of expression of the serotonergic2C receptor messenger RNA in the basal ganglia of adult rats. J Comp Neurol 384: 233-247.

Goldstein JM, Litwin LC, Sutton EB, Malick JB (1993). Seroquel: electrophysiological profile of a potential atypical antipsychotic. Psychopharmacology 112: 293-298.

Gonon F (1988). Nonlinear relationship between impulse flow and dopamine released by rat midbrain dopaminergic neurones as studied by in vivo electrochemistry. Neuroscience 24: 19-28.

Grace AA (1992). The depolarization block hypothesis of neuroleptic action: implications for the etiology and treatment of schizophrenia. J Neural Trans (Suppl) 36: 91-131.

Grace AA, Bunney BS, Moore H, Todd CL (1997). Dopamine-cell depolarization block as a model for the therapeutic actions of antipsychotic drugs. Trends Neurosci 20: 31-37.

Hedou G, Feldon J, Heidbreder CA (1999). Effects of cocaine on dopamine in sub-regions of the rat prefrontal cortex and their efferents to subterritories of the nucleus accumbens. Eur $J$ Pharmacol 372: 143-155.

Heidbreder CA, Hedou G, Feldon J (1999). Behavioural neurochemistry reveals a new functional dichotomy in the shell subregion of the nucleus accumbens. Prog Neuro-Psychopharmacol Biol Psychiatry 23: 99-132.

Hernandez L, Hoebel BG (1995). Chronic clozapine selectively decreases prefrontal cortex dopamine as shown by simultaneous cortical, accumbens and striatal microdialysis in freely moving rats. Psychopharmacol Biochem Behav 52: 581-589.

Herrick-Davis K, Grinde E, Teitler M (2000). Inverse agonist activity of atypical antipsychotic drugs at human 5-hydroxytryptamine2C receptors. J Pharmacol Exp Therap 295: 226-232. 
Horger BA, Elsworth JD, Roth RW (1995). Selective increase in dopamine utilisation in the shell subdivision of the nucleus accumbens by the benzodiazepine inverse agonist FG 7142 . J Neurochem 65: 770-774.

Hurley MJ, Stubbs CM, Jenner P, Marsden CD (1996). Dopamine D3 receptors are not involved in the induction of c-fos mRNA by neuroleptic drugs: comparison of the dopamine D3 receptor antagonist GR-103691 with typical and atypical neuroleptics. Eur J Pharmacol 318: 283-293.

Ichikawa J, Meltzer HY (1990). The effect of chronic clozapine and haloperidol on basal dopamine release and metabolism in rat striatum and nucleus accumbens studies by in vivo microdialysis. Eur J Pharmacol 176: 371-374.

Invernizzi R, Pozzi R, Samanin R (1995). Further studies on the effects of chronic clozapine on regional extracellular dopamine levels in the brain of conscious animals. Brain Res 670: 165-168.

Kalivas PW, Duffy P (1995). Selective activation of dopamine transmission in the shell of the nucleus accumbens by stress. Brain Res 675: 325-328.

King D, Zigmond MJ, Finlay JM (1997). Effects of dopamine depletion in the medial prefrontal cortex on the stress-induced increase in extracellular dopamine in the nucleus accumbens core and shell. Neuroscience 77: 141-153.

Marcus MM, Nomikos GG, Svensson TH (1996). Differential actions of typical and atypical antipsychotic drugs on dopamine release in the core and shell of the nucleus accumbens. Eur Neuropsychopharmacol 6: 29-39.

Marcus MM, Nomikos GG, Svensson TH (2000). Effects of atypical antipsychotic drugs on dopamine output in the shell and core of the nucleus accumbens: role of 5-HT2A and $\alpha 1$-adrenoceptor antagonism. Eur Neuropsychopharmacol 10: 245-253.

Merchant KM, Dorsa DM (1993). Differential induction of C-Fos gene expression by typical versus atypical antipsychotics. Proc Natl Acad Sci USA 90: 3447-3451.

Meredith GE, Agolia R, Arts MPM, Groenewegen HJ, Zahm DS (1992). Morphological differences between projection neurons of the core and shell in the nucleus accumbens of the rat. Neuroscience 50: 149-162.

Moore H, Todd CL, Grace A (1998). Striatal extracellular dopamine levels in rats with haloperidol-induced depolarization block of substantia nigra dopamine neurones. J Neurosci 18: 5068-5077.

Nomikos GG, Iurlo M, Andersson JL, Kimura K, Svensson T (1994). Systemic administration of amperozide, a new atypical antipsychotic drug, preferentially increases dopaminerggic release in the rat medial prefrontal cortex. Psychopharmacology 115: $147-156$.

Paxinos G, Watson C (1986). The Rat Brain in Stereotaxic Coordinates. Academic Press: London.

Pazos A, Palacios JM (1985). Quantitative autoradiographic mapping of serotonin receptors in the rat brain: I. Serotonin-1 receptors. Brain Res 346: 205-230.

Pontieri FE, Tanda G, Di Chiara G (1995). Intravenous cocaine, morphine, and amphetamine preferentially increase extracellular dopamine in the 'shell' as compared with the 'core' of the rat nucleus accumbens. Proc Natl Acad Sci USA 92: 12304-12308.

Rebec GV (1998). Real-time assessments of dopamine function during behaviour: single-unit recording, iontophoresis, and fastscan cyclic voltammetry in awake, unrestrained rats. Alcohol Clin Exp Res 22: 32-40.

Rebec GV, Christensen JR, Guerra C, Bardo MT (1997). Regional and temporal differences in real-time dopamine efflux in the nucleus accumbens during free-choice novelty. Brain Res 776: 61-67.

Skarsfeldt T (1988). Differential effects after repeated treatment with haloperidol, clozapine, thioridazine and tefludazine on SNC and VTA dopamine neurones in rats. Life Sci 42: 1037-1044.

Stockton ME, Rasmussen K (1996). Electrophysiological effects of olanzapine, a novel atypical antipsychotic, on A9 and A10 dopamine neurons. Neuropsychopharmacology 14: 97-104.

Werme M, Ringholm A, Olson L, Brené S (2000). Differential patterns of induction of NGFI-B, Nor1 and c-fos mRNAs in striatal sub-regions by haloperidol and clozapine. Brain Res 863: 112-119.

White FJ, Wang RY (1983). Differential effects of classical and atypical antipsychotic drugs on A9 and A10 dopamine neurones. Science 225: 1054-1057.

Wood MD, Reavill C, Trail B, Wilson A, Stean T, Kennett GA et al (2001). SB-243213; a selective 5-HT2C receptor inverse agonist with improved anxiolytic profile: lack of tolerance and withdrawal anxiety. Neuropharmacology 41: 186-199.

Zahm DS (2000). An integrative neuroanatomical perspective on some subcortical substrates of adaptive responding with emphasis on the nucleus accumbens. Neurosci Biobehav Rev 24: $85-105$. 